\title{
Policy as Boundary Object: A New Way to Look at Educational Policy Design and Implementation
}

\author{
Gholamreza Emad • Wolff -Michael Roth
}

Received: 11 December 2007 / Accepted: 23 September 2008 /

Published online: 7 October 2008

(C) Springer Science + Business Media B.V. 2008

\begin{abstract}
Policy implementation research in general and educational policy in particular is loosely connected to policy-making processes. There is a gap particularly in the field of vocational education. This often leads to conflicts and contradictions between policy-maker objectives and end-user implementation. To avoid such a disconnect, the relation between the world of end users and the world of decision-makers should be carefully constructed. This might be done through connecting the process of decision-making to implementation and carefully developing methods that encompass the demands of decision-makers and the needs and informational requirements of end users. Our intensive case study research on the process of a vocational education reform in the marine sector confirms that the lack of robust connection and active engagement of implementers as the end-users in the design of the policy created challenges for its implementation. Using a theoretical framework based on the notion of boundary objects we bring an alternative to current practice by creating the potential to illuminate and remove tensions and challenges for policy implementation. From there we infer that adopting this concept for policy design may prevent such conflicts and contradictions and result in successful implementation.
\end{abstract}

Keywords Maritime domain · Vocational education · Boundary organization · Educational policy $\cdot$ Boundary objects $\cdot$ Policy design $\cdot$ Policy implementation

\footnotetext{
G. Emad $(\bowtie)$

Faculty of Education, University of Victoria, MacLaurin Building A420, Victoria, BC V8W 3N4, Canada

e-mail: emad@uvic.ca

W-M. Roth

Applied Cognitive Science, University of Victoria, MacLaurin Building A548, Victoria,

BC V8W 3N4, Canada

e-mail: mroth@uvic.ca
} 


\section{Introduction}

The design and implementation of educational policies are not as easily separable as it might seem on first sight. Policy designers have much at stake in the final use of their policies, whereas users' actions are greatly mediated by the structural design of the policy that they implement. Many policies failed because their designers conceive implementation 'as a process that takes place after, and independent of, the design of policy' (Pressman and Wildavsky 1984, p. 143). Although policy implementation problems should be considered at the time of their design, there is not much to be found in implementation literature to guide the process (Elmore 2000). The list of the existing literature concerning 'implementation research is long on description and short on prescription' (p. 80). In this article, we propose to fill this gap by exploring the effect that the design of educational policies may have on schools at the time of their implementation. We then suggest a new way of contemplating the problem in order to develop possible remedies. In pursuit of this purpose, we focus on a policy intended for maritime vocational education and investigate its effect on training institutes during the course of its implementation. We exemplify some of the implementation challenges from the perspective of the practitioners in a maritime training institute. Using the theoretical concept of boundary objects, to examine the current status of a maritime educational policy, we demonstrate how using this concept bestows us a suitable tool to analyze the status of an educational policy and propose solution to remove the contradictions that we detect. From there we suggest that the use of this concept at the time of design may prevent creation of these contradictions and make the process of implementation more successful.

The concept of boundary objects refer to objects that serve as an interface between different social worlds (Star and Griesemer 1989). These are entities that cross the boundaries of different communities. In the process, and despite frequently different practices analogous to the object, the different communities come to be articulated and coordinated. Boundary objects therefore are objects that inhabit intersecting social worlds while at the same time satisfying the specific informational requirements and practices of each group (Bowker and Star 1999).

In this article, we discuss the benefits of considering the educational policy as a boundary object and confer the effects it may have on its design and implementation. To do that - following a description of the historical background - we focus on the social worlds of designers and users that influence the development of a policy. Next, the emphasis shifts to the policy itself and the contradictions it creates for its users. We investigate how in designing a policy the concept of boundary objects may reduce or remove those obstructions. We then identify a group of documents, which historically exist in the maritime educational domain and can be contemplated as boundary objects, and discuss the effect they had on the implementation process of a former policy. We conclude that there are possibilities for experimentation and further research in this area.

The study of maritime education is important because it can accord us a better understanding of implication of a large scale vocational educational policy, as all the maritime educational systems around the world have to pursue the same international educational standards. With an increasing globalization in all aspects 
of human life, moving toward a worldwide educational system is not far from reality. The study of maritime education, which has already undergone internationalization, would ameliorate our understanding of this phenomenon's process.

\section{Background}

During the 1960s, there was a great interest in large-scale educational reform around the world (Fullan 2000). The urgent reason was that the increasingly globalized world is increasingly complex, requiring educated citizens who can learn continuously (Drucker 1999), and who work in diverse conditions locally and internationally. The maritime domain ${ }^{1}$, as an active element of the global society, was under the same pressure to reform. This pressure intensified after a series of shipping accidents with colossal environmental damages during late 1960s and early 1970s (e.g., the Torrey Canyon in 1967). The subsequent investigations concluded that mariners' errors resulting from poor training and lack of competencies were the main causes of these accidents. Reform efforts therefore were urged to focus on ameliorating maritime education and training. Hence, the maritime domain started harmonizing and regulating its educational standards worldwide.

The International Maritime Organisation (IMO) - a technical agency of the United Nation - sets standards and harmonizes all the international maritime activities, including training and qualification of mariners who navigate ships. In 1978, the IMO introduced its first educational standards in the form of an international convention - the Standards of Training, Certification and Watch Keeping for Seafarers (STCW78). It was considered a breakthrough, as there were virtually no international standards in maritime training and certification thereat. After almost two decades of its implementations worldwide, the convention was not promoting the changes it initially designed to make - meaning it has not reached its objectives (e.g., Lewarn 1999; McCarter 1999; Moreby 1999; Zec et al. 2000). Some of the rationales claimed for its failure include (a) the terms and provisions in the convention were vague and opened to diverse interpretation; (b) the education method introduced by the policy was not suitable for marine vocation; (c) the policy itself was not clear about the responsibilities of different parties; and (d) the compliance to the convention was left to the satisfaction of maritime administrator of each country (Sperling 1997). Hence, the convention was futile in harmonizing maritime education and training standards around the world. To overcome these shortcomings - and motivated by the international concerns for development and transformation of vocational education and training systems during the 1990's (Lindell 2006) - the IMO made a comprehensive revision to its educational convention. It results in virtually creating a new convention known as STCW95 (IMO 2002). The STCW95 convention seeks to rectify the shortcomings of its predecessor in many ways (Sampson 2004). For example it introduces a different concept of education and training for mariners, namely competency-based training

\footnotetext{
${ }^{1}$ For the purpose of this article maritime domain includes all maritime-related activities, infrastructure, people and vessels.
} 
and education (CBT). It defines the competencies that a mariner should procure and demonstrate to be certified. The convention also aims to clarify the responsibilities of each party (government) (IMO 1996).

According to the convention each country should create its national maritime vocational educational policy based on the requirements of the STCW95 convention. Collective successful implementation of these national policies was to result in successful implementation of the Convention. However, it became evident sometime after the introduction of STCW95 that many countries faced with difficulties in fulfilling the requirements of the new system (Chawla 2006; Kanji 2000; Nakazawa 2000; Wilson 2007). These countries have challenges in implementing their national maritime educational policies. Recent surveys, by different countries and organizations, are evidence to the failure of the maritime educational system and the implementation of its national policies. It revealed that many of the mariners trained and holding the related certificate lack the required competencies (IMO NEWS 2006; SEAWAYS 2006).

\section{Theoretical Framework}

Educational systems are heterogeneous and different kinds of worlds involve in constructing the settings in which they are relevant. They tend to deploy multiple organizations and employ many actors (stakeholders); each has its own characteristic, view points, community and culture. Each community engages in its own activity within its boundary, but needs to work collaboratively with others. These communities cross each other's boundaries to be able to constitute the society we live in and experience on a day-to-day basis. Thus the design of an educational policy is embedded in larger social and cultural processes, which involves negotiation, persuasion, and lobbying (Garrety and Badham 1999).

The basic assumption, among many scholars in policy research, is that the policy design is fundamentally a process of collaboration and negotiation (e.g. Deelstra et al. 2003). Cooperating while having diversity and different viewpoints 'make the potential for conflict', tensions, and contradictions, which may result in a lack of consent between parties (Easterbrook et al. 1993, p. 2). Educational policymakers, who do not carefully contemplate these factors, may cause actors (stakeholders) to experience difficulties in reaching the objectives of their policies. Hence policy design should distinguish and consider needs, capabilities, interests, and effects of each culture. The question is how can these communities with different concerns, languages, forms of interaction, and practices succeed in cooperation? And how can their actions be managed to achieve accordance and get the work done? For this, we need a method that specifically accounts for the diversity of worldviews and justifies the miscellany of cultures.

The concept of boundary objects precisely evolved to understand what happens when different cultures and communities come into contact and the different understandings that emerge when people from these communities use the 'same' artifacts (e.g. Corcoran 1992; Fujimura 1988). Boundary objects are defined as entities (forms to be filled, objects, design plans used in different places of a production company) that move between communities (cultures) where they entail 
different practices and understandings. Or, in other words, when entities give rise to different practices (understandings), a boundary can be identified. Pragmatically, boundary objects can be used to connect different perspectives and viewpoints (Harvey 1997). For example, data collected by different individuals-e.g., hunters, naturalists, ecologists, and geologists - about some natural environments become comparable when the same data collection forms are used (Star and Griesemer 1989). Research shows that in such situations, different communities share boundary objects but may view or use it differently (Bragd 2002). Yet, at the same time, the boundary object coordinates and articulates these different understandings and uses. Thus, for example, engineering drawings play a mediating role in connecting communities of designers and builders while enabling them to communicate and conduct their works (Bechky 2003). According to this framework creating boundary objects, which are both adoptable to different viewpoints and robust enough to maintain their identity across them (Star 1989), is one activity that helps translate between viewpoints and resolving tensions (Bowker and Star 1999). The term boundary object therefore is an analytic concept for those objects that inhibit several intersecting social worlds and satisfy the informational requirements of each of them. Boundary objects foster interactions and cooperative work between social worlds and 'facilitate the translation of one group's interests into interests of other groups' (Fujimura 1992, p. 192). In the context of our study, we contemplate a vocational educational policy to be a boundary object. It is because it crosses the boundaries of different communities - policymakers and policy users - in which they orient different forms of activities while facilitating the communication between them.

Creation and management of an authentic boundary object needs collaborative work and communication between the respective communities (Star 1989). A number of studies have identified the importance of boundary work, and managing the interactions between social worlds, to make the collaboration possible. It has to be done where the boundaries, that separate the communities of decision makers and experts, cross (Cash 2001; Gieryn 1995; Jasanoff 1987). There is a need for managing boundaries between communities when boundary crossing happens (Cash et al. 2003). The boundaries of the intersecting areas of these communities can be managed effectively through (a) communication between people and across communities (b) translation of the language-local exchange language (Gallison 1997) - experience, and presuppositions of both sides, and (c) mediation act to make processes transparent, bringing all perspectives to the table, and establishing criteria for decision making. These functions can be institutionalized in boundary organizations (Cash et al. 2003). A boundary organization, mediates new boundary negotiations in its routine work, and stabilizes the boundary by performing successfully as an agent for both policymakers and practitioners (Carr and Wilkinson 2005) through creating and/or managing boundary objects.

Individuals (instead of an organization) can also perform the analogous concept. Different terms such as boundary analyst (Garraway 2006) and organizational translator (Brown and Duguid 2001) are proposed by scholars for individuals who can frame the interests of one community in terms of another communities' perspectives. Boundary spanner (e.g. Kleinman 1995; Lewenstein 1991; Moore 1996; Wolfle 1989) is yet other term suggested for the people who manage and bridge the gap between multiple organizations and communities (Hirsch 1972). 


\section{Method}

This study explores the design of a maritime vocational educational policy and challenges it created for end users at the time of its implementation. Our research is based on an ethnographic case study conducted in a maritime training institute in Canada. The study is part of a larger research designed to better understand the apparent contradictions in the maritime vocational education and training system specifically designed to increase the competencies of practitioners - mariners - with an overall goal to ameliorate that system.

Our database was established during the school years of 2005-2006 and 20062007. It consists of video recordings and field notes of eight dissimilar courses offered to different groups of mariners applying for certificate of competency. These include theoretical, practical, simulation, and technical courses. Participants were from both genders, but most were male. Courses were conducted in classroom, simulator, computer lab, and some of technical courses in their related fields-e.g. swimming pool and firefighting field. The numbers of students in each course were varied from 10 to 17 except for the simulation courses, which were limited to much smaller groups. Course lengths varied between 3 days to 20 weeks. All students were mariners and had prior practical experience onboard ships. The attendants of some of the courses consisted of mariners who already obtained the first level of maritime certification. They worked as ship's navigation officers for a period of time and in attempt to advance their certification to the next level were attending upgrading courses. Instructors were professional mariners who used to work onboard ships as certified captain and officers.

Our database also includes field notes, videotaped interviews with students, mariners, school administrator, course designers, and lecturers. We attended and videotaped all students' activities during the conduction of courses. Documents such as STCW Convention, national maritime educational policy, course syllabus, certification procedures, and relevant rules and regulations are also incorporated in our analysis for the purpose of this study.

\section{National Maritime Educational Policy as a Boundary Object}

The STCW95 Convention is an international treaty, which sets maritime educational standards. Countries that are parties to the convention-which includes almost all the maritime nations around the world-are bound to its content. Therefore, each country has to accommodate the requirements of the convention into their national legislation, which would comprise their national maritime educational policy. For Canada, Transport Canada is the maritime administration responsible for organizing and regulating the standards sets in the Convention in the country. To do that Transport Canada designed a national maritime educational policy. The focal point of this policy is the certification system. It requires mariners to have a Certificate of Competency to show that they are competent and permitted to work on-board ships. The maritime administration is responsible body for issuing the Certificate of Competency after verifying that a candidate is competent and meets certain requirements. In current practice mariners are required to attend approved maritime 
courses and those who have passed the examinations to be certified. In turn, the maritime institutes have to fulfill the requirements of the national maritime educational policy to get approval for their courses from maritime administrator. They have to fulfill the requisites of the national maritime educational policy, or in other words, implement that policy.

The characteristics of the national policy are analogous to the concept of boundary objects. The national policy is a document for the use of different communities in the maritime domain including mariners, training institutes, and maritime administrator. Maritime schools utilize it as a source for designing their courses and for modifying their teaching practices. This policy is nonetheless a working document for the maritime administrator. The maritime administrator employs the policy as a standing document, which is a reference for assessing the competencies of the mariners and issuance of the Certificate of Competency. It also provides a benchmark to check the performance of schools. Schools and administrators are part of different communities, which engaged in diverse activities. As the school program leader in our research noted, they have different mandates toward the same policy:

Yeah, different mandates, their mandate is to produce Canadian certified officers and that's strictly what it is, and our mandate as an education facility is to produce a product that's able to work in the work force today. So they are looking at a piece of paper and we're looking at what makes up that piece of paper.

The same national policy therefore is an artifact that serves disparate communities for different mandates, based on their mission, practice and worldview while it retains it integrity. The theoretical concept of boundary object suggests that when the same entity appears and is used in different communities, one should not be astounded to see different practices surrounding the object. Whereas the boundary object can be used to articulate, join, translate, and mediate between the two different practices, these nevertheless become the same, which means that the same documents leads to different actions. Albeit having different mandates and viewpoints, the participants of the different communities have to cooperate to reach the same objective of implementing the requirement of the policy and producing competent certified mariners. In other words the policy that both communities use resides where the boundaries of these communities crosses each other. As the policy document both defines and creates the boundaries, it has a complex nature, which delineates and creates different worlds (Law 2004). Yet as a boundary object it has to be understandable, adaptable and elucidate to all of them.

\section{Challenges with the National Maritime Educational Policy}

Our study shows that schools encountered many difficulties in their attempt to implement the requirements of the national maritime educational policy. These difficulties and challenges, so we found, are resulting from the fact that the administrator designed the policy in isolation. There are flaws in the design and structure of the policy. The lack of active communication between the administration 
and schools intensifies the effect of these flaws and reduces the possibilities for improvement. In the following, we discuss the related challenges we found in our study.

\section{Ambiguously Experienced Terms and Objectives}

A major dilemma our study revealed is due to the fact that the maritime administrator has created the national maritime educational policy mainly by directly transferring the content of the convention into its policy format. On the user side, the unfamiliarity of the content-related language led users to experience ambiguity of the terms and objectives described in the policy document. For instance, Ian, maritime school administrator noted:

So of course what Transport Canada does, they take STCW objectives and the code itself, the STCW code, and to make that something as a standing documents of Canada they take that and injected it into their own system.

Little effort has been made for adjusting the policy to the language, current practice, and culture of the maritime educational institutes in the country. This, as many participants in our study pointed out, constitutes a major problem. One of the drawbacks is that in the college the policy is judged to be too broad, vague, and ambiguous. Thus, one course designer said, 'So that's how vague this syllabus is. We get no other information on this to put together a course. I have to put a course together based on this.' The designers have to fashion their curriculums based on objectives that are not clear to them. They expressed their concerns about the fact that the terms and objectives expressed in the policy are brief and hence open to very different interpretations. As one course designer and instructor suggested:

Transport Canada will tell me (i.e., in the policy) that for this topic these are the types of the objectives you need to meet and a very brief. . Based on what that is, I need to generate a course to fulfill those very brief objectives that they have set.

These excerpts show that brief descriptions and the resultant vagueness of terms and objectives have created challenges for the schools to implement the policy. Furthermore, the absence of support from the administrator for the interpretation (translation) of the policy requirements made the situation even more problematic. The effect of clear objectives in implementation success is emphasized in the literature (e.g., Sabatier and Mazmanian 1979). These authors, in their attempt to integrate several previous conceptualizations into an extended model, pointed out that one of the most effective variables in policy implementation success is how precisely and consistently the objectives are specified and ranked.

Looking at the STCW95 document, one can see that the marine administrator in Canada uses the same terms and objectives that have been used in the Convention itself. They put in little effort for clarification, adjustment, and modification to the particulars of the country's contexts. The STCW Convention is also a document with the same characteristics as boundary object. It is designed to set a common set of standards to coordinate the related actions of maritime communities around the world. A boundary object should be both plastic enough to be adapted to the local 
needs and constraints of each of the several communities using it but robust enough to maintain a common identity across sites (Star 1989). STCW has to contemplate the informational requirements of maritime communities of different countries. As the informational needs, limitation and abilities, understandings, practices and cultures of the target communities are vast and greatly different the boundary object (STCW) has to be very plastic to accommodate these varieties. Global concepts, discourses, and policies have to have an underlying flexibility, transferability, and mobility (Lindell 2001) so that national reforms can be formulated in ways to fit the international context. This requires the terms to be broad and general to be adoptable by each community, and accord flexibility to the users to mold and adapt them to their varied practices and needs.

However, a national maritime educational policy addresses only a limited number of communities, mainly the maritime schools and administrator of a country. This artifact plays a different role than that which the STCW convention plays in its context. The standards, objectives and syllabus included in the policy have to be understood and implemented by relatively homogenous communities of schools of that country. These factors delineate the extent to which the object should be plastic. Transferring the content of one into another would create challenge for respective communities. STCW is a document showing the requirements of maritime educational system in general and each national maritime educational policy should be showing it country specific. Therefore, the STCW has to be flexible and plastic enough for maritime administrations of different countries to be able to reach accordance and adopt common standards. National policy on the other hand has to be more specific and detailed. Its terms and objectives have to be precise, understandable, and applicable for a relatively common culture of maritime training institutes in that country. The marine administrators are generally anticipated to act as mediators and translate the requirements of the STCW Convention for their implementers based on their needs, abilities, practices and cultures.

\section{Lack of Participation in Design}

Our data provide evidence that there exists a lack of effective communication at the time of design of the policy between the administrator and schools. Miscommunication continues after design and during the implementation process, and it creates dilemmas for schools in understanding and implementing policy. Thus, our participants complained: 'I am not given guidance from Transport Canada', 'I am not given information on which textbooks they use for their examinations and that will create difficulties' and, 'We get no other information on this to put together a course'.

Using the notion of boundary object in design of a policy requires the incorporation of viewpoints of its users in the design process. To be able to incorporate the viewpoints of its users the national maritime policy as a boundary object needs participation of all stakeholders in the design process. The effectiveness and the extent to which implementers have participated in the design of a policy are the critical factors affecting the degree of its success (Gross et al. 1979). The reasons that they advert to, among others, the importance of the participation are as follows: (a) participation leads to higher staff morale which is necessary for successful 
implementation; (b) participation leads to greater commitment that is required for effecting changes; (c) participation leads to greater clarity about the goals and objectives of the policy which is necessary for implementation; (d) participation reduces initial resistance and thereby facilitates successful implementation; and (e) implementers tend to resist any innovation (King and Anderson 1995; Sabatier 1991) that they are expected to implement if it is initiated solely by their superiors. Successful policy needs parties to take effective part in the design, in this way, their view point, informational requirements, their abilities and constrains would be accounted for. 'When participants in the intersecting worlds create representations together, their different commitments and perceptions are resolved into representations' (Star and Griesemer 1989, p. 413). Effective participation and having a voice in the design help to set realistic and implementable objectives. In this way, the end users will take part in defining the terms and objectives and would be elucidate and cognizant about what they have to implement.

\section{Systemic Problem}

Our study reveals that the weakness of the maritime national educational policy goes further than its vagueness and ambiguity: its structure and processes also create problems for its implementers. The major dilemma that we found is with the assessment and evaluation process for certification (Emad and Roth 2008). As one of the instructors pointed out:

What I foresee today to be one of the biggest obstacles in the pathway for a learner . . . is the evaluation process ... That's a huge obstacle in this field.

This problem arises from the fact that the assessment system is separated from training and education so that it comes to be conducted solely by the administration; hence it created an obstacle for schools. The absence of users-especially the schools-during the design phase contributes to this flaw in the process of implementation. The current assessment for certification system presented in the policy, arranged by maritime administration, lead to an inner contradiction. Whereby it created another impediment and obstacle in the process of implementing the policy by schools. As a course designer and instructor also elaborate the problem:

From here my students after they complete my course they go back to Transport Canada to be examined and to me that's an obstacle, in that, umm, the level of education that's delivered to that learner is based on my experience and my interpretation of what that objective is.

The earlier dilemma of ambiguous objectives combined by the evaluation process presented in the policy created this impediment. Further investigation into the assessment system revealed that the disconnect between the designer and users caused inability of the administrator, as provider and conductor of the assessment, to afford an assessment, which is reliable and valid for the users, as an instructor exemplifies:

Quite often the examinations are reflecting history and haven't been updated. . . . So what I am having to do is trying to figure out what Transport Canada may 
want and what I end up doing is wasting lot of students and learners time teaching history instead of teaching today.

The excerpt shows that disconnect between policy designers and practitioners resulted in unrealistic and unexpected demands from the users. This, in turn, mediates the emergence of unwillingness and resistance on the part of training institutes and it creates virtual objectives ("trying to figure out what Transport Canada examiners may want") with resultant unauthentic implementation of the policy ("teaching history instead of teaching today").

Designing the policy by employing the framework of the boundary objects may help making the implementation process less problematic. It reduces the contradictions by negotiating agreed-upon terms, definitions, and procedures for achieving the objectives and incorporated viewpoints of all the users. According to our boundary object perspective, this policy could be made collaboratively by engaging all the parties. Mutual understanding of the work can in fact be realized between multiple perspectives through designing shared and practice-oriented artifacts (Suchman 1995). This approach has shown to be successful, for example, in Scandinavian workplace design. It brought together computer engineers and workers who collaboratively built a model that embodied shared understandings, which the engineers subsequently translated into their native language (Ehn 1992). That is, the shared artifacts and associated language became a boundary object that allowed all participants to translate between the particular languages of their respective communities. Hence, there is a definite need for the creation and use of shared artifacts and the structuring of communicative, and collaborative practices among all the stakeholders. In the next section, we elucidate how these collaborative works could be done and managed, and discuss utilizing the existing possibilities.

\section{Toward Collaborative Work}

Collaboration among different communities for creating an authentic boundary object is a necessity yet establishing an effective collaborative work is challenging (Star 1989). Creating networks that link together different members of a community (e.g. maritime training institutes) can facilitate the work required for the articulation of different communities (Lewarn 1999). Establishing a forum or association is a key factor in sustaining and ameliorating the successful networking. This can be a venue for effective communication among training institutes and between the institutes and the maritime administration. Our study reveals that there are analogous concerns among maritime institutes. Resulting from presence of the common problem of implementation among schools they started a communicative process to discuss their dilemmas and share their ideas with other members of their community (i.e. other maritime training institutes). The outcome of the process was the creation of an association that serves to facilitate the interaction between the members to reach a concord toward the implementation. It also facilitates a common and unified voice, which could effectively communicate with the administrator for discussing their concerns.

The association consists of major maritime training institutes in the country. They meet few times a year to discuss their problems and concerns and to reach accords. The training institutes attempt to negotiate the implication of their concerns with the 
maritime administration, as suggested by the school program leader in the institute we studied:

Across Canada the seven major institutions we formed an association, Canadian Association of Marine Training Institutions (CAMTI) and twice a year we meet with Transport Canada on Ottawa. I just got back two weeks ago, and we do it in November and we meet again late April into May. So we meet with Transport Canada, and we discuss issues, like this one, and umm I would get still, what we get afterward is sometimes ((laughs)) sometimes a different story. But, there is an opportunity for concerns to be addressed.

As the excerpt shows the outcomes of these meetings are discussed with the marine administrator. Yet, although there currently is a relationship, it turns out not to be always effective and producing fruitful results. Even though it was not fully functional at that stage, this association has the potential of playing the effective managing and communicative role it intends to do. It has the capability to facilitate organizing the boundaries between administrator and training institutes when they cross.

\section{CAMTI as a Legitimate Boundary Organization}

CAMTI is a legitimate organization created by and representing the maritime training institutes and can be contemplated as a boundary organization. It serves as a venue for negotiation and mediation among training institutes and between training institutes and the marine administration. A boundary organization could provide a forum in which information can be co-produced by actors from different sides (Guston 1999) and help manage the use of boundary object (policy).

Our research follow-ups show that in the course of time the meetings (between CAMTI and marine administrator) become more meaningful and constitute authentic engagement of different sides. One of the main factors that had a noticeable effect on the willingness for productive collaboration of both parties was the constraint to meet certain deadlines regarding the implementation of different phase of the policyespecially by the maritime administration. This along with other timelines set by a supervisory national organization compel, motivated and drove more effective cooperative work and more productive communication. Our investigation reveals that there have been outcomes from the current meetings that created positive results toward implementation of the policy.

In the next section, we discuss exemplary historical evidence in international maritime domain that we encountered in our study for collaborative work and successful creation and use of documents that can be contemplated as boundary objects. We elaborate and argue the rationales for its relatively successful effect on the implementation of national maritime educational policies based on the earlier version of the STCW convention in some countries.

\section{Model Courses as Boundary Objects}

Historically, the maritime educational domain is not unfamiliar with the objects that has been created and performed analogous function as boundary objects. During the 
1980s after introducing STCW78 convention, many countries expressed difficulties with respect to the implementation of the convention. One of the main concerns pertained to the ambiguity of the convention's objectives and thus to the criteria for the competencies that mariners have to achieve. The recommendation proposed was the creation of a set of documents, which elucidate the competencies and express standards that were to be achieved in a clear and detailed format, namely, model courses. They created the model courses through the consultation and cooperation of maritime institutes and marine administrators of a group of countries.

After its introduction, many maritime administrators recommended to schools in their countries to use these model courses as a guide for designing their courses. A model course is basically a clearly delineated teaching syllabus and a detailed lesson plan of a maritime course. These became a source for resolving the conflicts caused by different interpretation of objectives as they bestowed administrators, and therefore schools, a clear indication of what has to be achieved. Canada was one of the countries whose educational system showed a good matched with the format of the model courses. Our study shows that maritime training institutes were familiar with that, and most of their course designers used the model courses for the implementation of the earlier version of policy. Thus, one course designer participated in our study suggested:

So for navigation when I am looking at this topic right here. I am looking at charts or umm, pilotage [names of different courses] that block right there [he was looking and pointing at a part of a related model course]... for pilotage there is six or eight pages in here [compare to one small paragraph in related section of the national maritime educational policy - TP2293] so here is very defined. For example when you look at this [TP2293] a thorough knowledge of; now look at here [model course] a thorough knowledge defined as: being able to define this; being able to explain this; being able to use this; proper descriptive verbs. Now this is a usable document to me. This is very clear to me. I can fulfill these requirements then I can achieve the task. Unfortunately, these don't directly relate to that [current national policy].

The excerpt shows that the model courses, which have been prepared by collaboration of end users especially schools, played a very important role in designing courses. The course designer was confident in using the model courses. These documents expressed the objectives clearly, which reduced ambiguity and at the same time it also fulfilled the informational needs of the schools. These are the functions of boundary objects.

\section{Failure of Model Courses in Some of the Countries}

Controversies regarding the use of model courses exist sometimes after its introduction by a group of countries around the world. The literature provides evidence for concerns of the use of model courses in those countries (e.g., Horck 2003; Lewarn 2002). Engagement and cooperation of only a small number of countries (as end users) in design and preparation of model courses probably resulted in limited applicability of those objects by other countries. As capabilities, interest, and educational systems were varied and extensively diverse, model courses mainly 
served maritime administration and schools in the countries that participated in creation of those documents and have their view points and informational requirements incorporated. This makes immediate sense in the present framework, when we take the documents to be collaboratively designed boundary objects. In this case, the boundary objects embody language and needs of the participants, while likely failing to do so in the case of non-participants. It also assists that group of countries, which had commonalities and similar educational system with the format incorporated in the model courses.

Based on our study, we do not recommend the creation and use of model courses on a large scale. It is not possible within a single set of documents to accommodate in detail all the needs, view points, and informational requirement of every stakeholder in a large and diverse user group. Instead, we suggest that the supplementary documents for current policy can be prepared at the national or regional levels by the cooperation of all users, and especially by the cooperation of training institutes and maritime administration in that region or country. They could use the boundary object criteria in creating the documents. It could easily incorporate the same format that the national or regional educational system requires. Such documents might have sufficient plasticity to accommodate the provisions for further modification and updating content of each course or the delivery method and also contemplate the current and future need of marine industry (Beer and Meethan 2007). As it is prepared locally it could take into account the present educational culture, experiences, criteria and limitations so it would be a produce useable by the same educational community.

\section{Discussion and Suggestions}

This interpretive case study illustrates how educational policy can be seen as boundary object that connect disparate communities and by doing so allows them to communicate and cross each other's boundaries. In this study, we exemplify some of the challenges in maritime vocational education system and its reform from the perspective of practitioners. We discuss that the national maritime educational policy, which is prepared by the maritime administrator created challenges for maritime schools. Using the notion of boundary object, we discuss the possible rationale for the unsuccessful educational policy is that the maritime administration did not consider the view points and informational requirements of the schools in the design process of the policy. This study shows that the framework of boundary objects has the potential to expose tensions and challenges of policy implementation. It is from these tensions that policy execution can be reviewed and subsequently revised.

We did not have the opportunity to analyze a policy which is created based on the concept of boundary object but our careful analysis of the contradictions and shortcomings of a vocational educational policy leads us to believe that the use of this concept at the time of design might have prevented those problems. Our work implies possible benefits from using the analytical concept of boundary object in the creation of educational policies. It deliberates the concerns of all the parties needs to be preserved if they were to continue fully participating. A possible way of reducing implementation challenges of the present national maritime educational policy is its 
redesign or adjustment using the theoretical framework of boundary object. It would be an opportunity for the maritime administration to recreate the policy as boundary objects. This may lead to reducing the current challenges that the current policy created and increase the possibilities of a successful implementation. The creation of the national policy as a boundary object needs representation of the schools - and preferably other stakeholders - to work closely with maritime administration. When participants in the intersecting world create representations together, their different commitments and perceptions are resolved into representation. If there are difficulties, such as political constraints, in modification of the national policy then we suggest that the parties collaboratively create a new boundary object, which can supplement the policy-as guidelines or instruction-by participation of all stakeholders with the goal of successful implementation of the agreed upon objectives of the current national maritime educational policy. Our research also suggests the need for managing the boundaries through effective communication, translation, and mediation when crossing from maritime administration into schools at the time of modification or supplementation. Our model may fit best when the end users are not in acute competition and willing to participate authentically. That is, wishing to arrive at collaborative solutions that are in the common interest rather than reflecting only the partial interests of this or that stakeholder.

How effective these can be remains a question for a further scholarly research. The historical evidence regarding the successful use of model courses, which followed a concept analogous to what we proposed, bestows an exemplary case for prediction of positive outcome of our proposal for analogous situations. The further research can be done using the method of boundary-crossing laboratories (Engeström 2001). In such laboratories, different social worlds are brought together in a controlled environment to discuss the salient problems at hand. These are then videotaped and analyzed by researchers, and enabling and disabling actions highlighted at follow up meetings for further discussions. This method has proven to be successful in developing workable solutions. The idea of this type of study for the development of a more responsive educational policy is a potentially interesting and useful idea for future research.

Acknowledgment The authors would like to acknowledge that part of this research funded by WorksafeBC, Canada.

\section{References}

Bechky, B. A. (2003). Object lessons: workplace artifacts as representations of occupational jurisdiction. American Journal of Sociology, 109, 720-752. doi:10.1086/379527.

Beer, J., \& Meethan, K. (2007). Marine and maritime sector skills shortages in the south west of England: Developing regional training provision. Vocational Education \& Training, 5(4), 467-484. doi:10.1080/13636820701650935.

Bowker, G. C., \& Star, S. L. (1999). Sorting things out: Classification and its consequences. Cambridge MA: MIT,

Bragd, A. (2002). Knowing management. An ethnographic study of tinkering with a new car. Göteborg: BAS Publisher.

Brown, J. S., \& Duguid, P. (2001). Structure and spontaneity: Knowledge and organization. In I. Nonaka, \& D. Teece (Eds.), Managing industrial knowledge (pp. 44-67). London: Sage Publication. 
Carr, A., \& Wilkinson, R. (2005). Beyond participation: boundary organizations as a new space for farmers and scientists to interact. Society \& Natural Resources, 18, 255-265. doi:10.1080/ 08941920590908123.

Cash, D. W. (2001). In Order to aid in diffusing useful and practical information: agricultural extension and boundary organizations. Science, Technology \& Human Values, 26(4), 431-453.

Cash, D. W., Clark, W. C., Alcock, F., Dickson, N. M., Eckley, N., Guston, D. H., Jäger, J., \& Mitchell, R. B. (2003). Knowledge systems for sustainable development. Proceedings of the National Academy of Sciences of the United States of America, 100(14), 8086-8091. doi:10.1073/pnas.1231332100.

Chawla, P. (2006). Crew shortage and qualified seafarers, SEAWAYS: The International Journal of The Nautical Institute, Feb, 16 and 21.

Corcoran, E. (1992). Building Networks. Scientific American, (Nov), 118-120.

Deelstra, Y., Nooteboom, S., Kohlmann, R., Berg, J. V. D., \& Innanen, S. (2003). Using knowledge for decision-making purposes in the context of large projects in the Netherlands. Environmental Impact Assessment Review, 23, 517-541. doi:10.1016/S0195-9255(03)00070-2.

Drucker, P. F. (1999). Managing challenges for the 21st century. Oxford: Butterworth - Heineman.

Easterbrook, S. M., Beck, E. E., Goodlet, J. S., Plowman, L., Sharples, M., \& Wood, C. C. (1993). A survey of empirical studies of conflict. In S. M. Easterbrook (Ed.), CSCW: Co-operation or Conflict? (pp. 1-68). London: Springer-Verlag.

Ehn, P. (1992). Scandinavian design: On participation and skill. In P. S. Adler, \& T. A. Winograd (Eds.), Usability: Turning technologies into tools (pp. 96-132). New York: Oxford University Press.

Elmore, R. F. (2000). Backward mapping: Implementation research and policy decision. In T. Miyakawa (Ed.), The science of public policy: Essential readings in Policy Sciences II Vol VI (pp. 80-96). New York: Routledge.

Emad, G., \& Roth, W. -M. (2008). Contradictions in the practices of training for and assessment of competency: a case study from the maritime domain. Journal of Education + Training, 50(3), 260-272.

Engeström, Y. (2001). Expansive learning at work: towards an activity theory reconceptualisation. Journal of Education and Work, 14(1), 133-156. doi:10.1080/13639080123238.

Fullan, M. (2000). The return of large-scale reform. Journal of Educational Change, 1, 5-28. doi:10.1023/ A:1010068703786.

Fujimura, J. H. (1988). The molecular biological bandwagon in cancer research: where social worlds meet. Social Problems, 35(3), 261-283. doi:10.1525/sp.1988.35.3.03a00050.

Fujimura, J. H. (1992). Crafting science: standardized packages, boundary objects, and translation. In A. Pickering (Ed.), Science as practice and culture pp. 168-211. Chicago: University of Chicago Press.

Gallison, P. (1997). Image and logic. Chicago: University of Chicago Press.

Garraway, J. (2006). Creating productive interactions between work and the academy. Higher Education, 52, 447-464. doi:10.1007/s10734-005-2378-3.

Garrety, K., \& Badham, R. (1999). Trajectories, social worlds, and boundary objects: A framework for analyzing the politics of Technology. Human Factors and Ergonomics in Manufacturing, 9(3), 277290. doi:10.1002/(SICI)1520-6564(199922)9:3<277::AID-HFM5>3.0.CO;2-F.

Gieryn, T. F. (1995). Boundaries of science. In S. Jasanoff, G. E. Markle, J. C. Petersen, \& T. Pinch (Eds.), Handbook of science and technology studies (pp. 393-443). Thousand Oaks, CA: Sage.

Gross, N., Giacquinta, J., \& Bernstein, M. (1979). Implementing organizational innovations: $A$ sociological analysis of planned educational change. Berkeley, CA: McCutchan.

Guston, D. H. (1999). Stabilizing the boundary between U.S. politics and science: the role of the office of technology transfer as a boundary organization. Social Studies of Science, 29(1), 87-112. doi:10.1177/ 030631299029001004.

Harvey, F. (1997). Improving multi-purpose GIS design: Participative design. In S. C. Hirtle, \& A. U. Frank (Eds.), Spatial information theory: A theoretical basis for GIS (pp. 313-328). New York: Springer.

Horck, J. (2003). International maritime legislation and model courses. International Association of Maritime Universities, 3(1), 1-13.

Hirsch, P. M. (1972). Processing fads and fashion: an organization-set analysis of cultural industry systems. American Journal of Sociology, 77, 639-659. doi:10.1086/225192.

IMO, (2002). International convention on standards of training, certification and watchkeeping for seafarers 1978. Retrieved August 20, 2007, from http://www.imo.org/Conventions/contents.asp? doc_id=651\&topic_id=257.

IMO. (1996). International convention on standards of training, certification and watchkeeping for seafarers 1978, as amended in 1995, and seafarer's training, certification and watchkeeping code. International Maritime Organization, London.

IMO NEWS (2006). STCW Set for major review, sub-committee agrees. IMO NEWS, 1, 24-25. 
Jasanoff, S. (1987). Contested boundaries in policy-relevant science. Social Studies of Science, 17, 195230. doi:10.1177/030631287017002001.

Kanji, G. (2000). Emerald now spotlight interview. Retrieved July 01, 2007, from http://www.mcb.co.uk/ emerald/now/spotlight.htm.

King, N., \& Anderson, N. R. (1995). Innovation and change in organizations. London: Routledge.

Kleinman, D. L. (1995). Politics on the endless frontier: Postwar research policy in the United States. Durham, N.C.: Duke University Press.

Law, J. (2004). After method: Mess in social science research. London: Routledge.

Lewarn, B. (1999). Maritime education and training - Can it meet the industry's demands for better qualified seafarers. Proceedings of Ship Management '99 Conference, (pp. 1-19), Singapore.

Lewarn, B. (2002). Seafarer training - Does the system defeat competence? Proceedings of the Third General Assembly of The International Association Of Maritime Universities, (pp. 23-26), Maine.

Lewenstein, B. V. (1991). The AAAS and scientific perspectives on public understanding 1945-1985. Paper presented at the annual meeting of the American Association for the Advancement of Science, Washington, D.C.

Lindell, M. (2001). Trends and development in VET systems: flexibility, transferability, and mobility issues. International Journal of Vocational Education and Training, 9(2), 33-46.

Lindell, M. (2006). From formulation to realization, the process of Swedish reform in advanced vocational education. Education + Training, 48(4), 222-233.

McCarter, P. (1999). STCW95: implementation issues. what is the pass mark? Marine Policy, 23, 11-24. doi:10.1016/S0308-597X(97)00046-8.

Moore, K. (1996). Organizing integrity: american science and the creation of public interest organizations 1955-1975. American Journal of Sociology, 101(6), 1592-1627. doi:10.1086/230868.

Moreby, D. H. (1999). Professionalisation. SEAWAYS: The International Journal of The Nautical Institute, July, 11-12.

Nakazawa, T. (2000). Academic education for marine engineering at advanced maritime universities. International Association of Maritime Universities Journal, 1(1), 40-44.

Pressman, J., \& Wildavsky, A. (1984). Implementation. Berkeley: University of California Press.

Sabatier, P., \& Mazmanian, D. (1979). The conditions of effective implementation: a guide to accomplishing policy objectives. Policy Analysis, 5(4), 481-504.

Sabatier, P. (1991). Toward better theories of the policy process. Political Science and Politics, 24(2), 144-156. doi:10.2307/419922.

Sampson, H. (2004). Romantic rhetoric, revisionist reality: the effectiveness of regulation in maritime education and training. Vocational Education and Training, 56(2), 245-268. doi:10.1080/ 13636820400200256.

SEAWAYS (2006). Bridging the gaps. The International Journal of The Nautical Institute, July, 2.

Sperling, G. H. (1997). New convention on standards of training, certification, and watchkeeping: What, if anything, does it mean. Tulane Maritime Law Journal, 22, 595-618.

Star, S. L. (1989). The structure of ill-structured solutions: Boundary objects and heterogeneous distributed problem solving. In L. Gasser, \& M. Huhns (Eds.), Distributed artificial intelligence (pp. 37-54). London: Pitman.

Star, S. L., \& Griesemer, J. R. (1989). Institutional ecology, 'Translations' and boundary objects: Amateurs and professionals in Berkeley's museum of vertebrate zoology. Social Studies of Science, 19, 387-420. doi:10.1177/030631289019003001.

Suchman, L. (1995). Making work visible. Communications of the ACM, 38(9), 56-64. doi:10.1145/ 223248.223263.

Wilson, T. (2007). STCW review. SEAWAYS: The International Journal of The Nautical Institute, Jan 7-10.

Wolfle, D. (1989). Renewing a scientific society: The American Association for the Advancement of Science from World War II to 1970. Washington, D.C.: American Academy for the Advancement of Science.

Zec, D., Komadina, P., \& Pritchard, B. (2000). Toward a global standard MET system - An analysis of the strengths and weaknesses of present MET systems. Proceedings of 1st International Association Of Maritime Universities, Inaugural General Assembly \& Congress, (pp. 140-146), Istanbul. 